\title{
La vie, document : un poème
}

\section{Philippe Beck}

\section{OpenEdition}

\section{Journals}

Édition électronique

URL : http://journals.openedition.org/alter/937

DOI : $10.4000 /$ alter.937

ISSN : 2558-7927

\section{Éditeur :}

Association ALTER, Archives Husserl (CNRS-UMR 8547)

\section{Édition imprimée}

Date de publication : 1 novembre 2013

Pagination : 29-31

ISBN : 978-2-95-223749-9

ISSN : 1249-8947

\section{Référence électronique}

Philippe Beck, «La vie, document : un poème », Alter [En ligne], 21 | 2013, mis en ligne le 01 juin 2013 consulté le 10 décembre 2020. URL : http://journals.openedition.org/alter/937 ; DOI : https://doi.org/ 10.4000/alter.937 
Philippe Beck fut l'un des membres fondateurs de la revue Alter, il y a vingt ans. Il publia dans Alter trois textes, dont l'un en deux livraisons, dans les premiers numéros. Il est poète, reçu, lu, commenté. C'est donc en parole de poète qu'est venue sa parole lors du colloque qui marqua les vingt ans de la Revue Alter. Le lecteur lira. Il lira cette parole ailleurs que dans la philosophie plus ou moins académique, très loin aussi de tout grand lyrisme inentamé ; parole très écrite et très chantante qui documente la vie - qui, indirectement, questionne l'indéracinable, l'entêtée naïveté phénoménologique ; celle qui veut dire la vie ; la vie pure - et qui plus est, croit y parvenir. Cette parole ailleurs parle la vie, la vie avant la réflexion - mais pas sans elle; la vie, rythme interrogatif du dire/dit - sans prosaïsme - dont l'immédiateté n'est pas transparence, qui contrarie sa capture en un vouloir-dire, sans l'annuler vraiment ; la vie qui inquiète l'entente - la contrarie un peu; et ne s'entend qu'ainsi. Si la vie est déjà poème, alors "la poésie est défunte", mais si "la vie est pré-poème», se souvenir que "pré-poème est silence de mort », et que "poème est boustrophe de la vie, après la phénoménologie ».

Un poème: lorsque les partages ne sont plus si nets (entre silence et éloquence, entre mort et vie - vie qui peut être «demi-vies partagées »), lorsque la résurrection est première, et l'expression, toujours une «impression dehors».

F.-D. S. 


\section{LA VIE, DOCUMENT : UN POÈME}

Philippe Beck

La vie est poème

ou pré-poème?

Une communauté réfléchie dit qu'elle est

déjà poème

silence marionnetiste,

comme le roman est déjà

supposément le drame des matières

premières de la conscience ouverte.

La conscience est couchée?

Ses couvertures sont vivantes?

Et le poème est Pinocchio?

Conscience régresse à l'infini dans la matière

d'une vie manipulante et sans voix?

Si la vie est poème, alors

la poésie, usine à phrases

dont le vers conscient est l'horizon,

est défunte : le silence de la vie

l'actionne ou l'active et dicte sa loi

aux mots liés, au Ruban Sorti,

aux lignes savantes qui laissent parler

et ne parlent plus.

Mais le poème, préparé dans la fin vivante du sile

parle et fait parler. Il appelle à d'autres lignes

sorties du silence défunt.

Pré-poème est silence de mort.

Poème est boustrophe de la vie

après la phénoménologie?

Si oui, Poème est document. 
Il apprend la vie qui est prose passive avant la poésie?

Le document importe ce qu'un premier silence refuse.

Le silence est peuplé de vie éloquente, et l'expression, une impression dehors.

La résurrectine est première ;

le poème est résurrectionnel, marionnette muette et refaite, parlante, avant les vies et les demi-vies partagées.

La vie première se pose seule comme une île dans la rétention longue.

Pourquoi des poèmes

si tout est déjàa isolé dans la vie?

La vie est une carpe?

Ile-de-la-Carpe?

Chacun doit le dire. 